\title{
Epic Health Record System
}

National Cancer Institute

\section{Source}

National Cancer Institute. Epic Health Record System. NCI Thesaurus. Code C105672.

Any of the electronic health record systems and solutions developed by the Epic corporation. 